\title{
Emotional Intelligence and Its Correlation with Job Satisfaction, Performance and Organizational Commitment among Medical Staff at Faculty of Medicine; Ain Shams University, Egypt
}

\author{
Hebat Allah MS. Gabal, Doaa M. Elhussiney
}

Department of Community, Environmental and Occupational Medicine, Faculty of Medicine, Ain Shams University, Ramsis Street, Abbaseya, Cairo 11566, Egypt

\begin{abstract}
Background: Emotional intelligence (EI) plays an important role in medicine and education. It improves the teacher's behavior and the success of their profession. Teachers are the main pillar in the educational system. They are the moderators through which the knowledge can be transferred to the students who represent the foundation of the society. Objective: To estimate the level of EI among staff at the faculty of medicine at Ain Shams University, to determine socio-demographic and work-related variables that might affect EI level and to find out the relation between EI and job satisfaction, job performance and organizational commitment. Method: A cross-sectional study was conducted among 300 medical staff at Faculty of Medicine in Ain Shams University; a standardized self-administrated questionnaire was used; gathered information on the respondents' demographic and job characteristics, standardized measures of emotional intelligence, job satisfaction, job performance, and organizational commitment respectively. Results: $89.3 \%$ of participants had a moderate level of EI and $82.0 \%$ had a moderate level of satisfaction. Age, gender, marital status, working department, and academic rank significantly affect EI level. There was a significant correlation between EI level and total job satisfaction score, job performance, normative and affective commitment. Conclusion: faculty members who had higher EI were more productive and satisfied by their work and more committed to their organization. Recommendation: holding regular educational workshops for the staff to promote their EI is mandatory. EI test should be used in the workplace for giving promotions, staff reviews, and recruitment.
\end{abstract}

Keywords: Emotional intelligence, Job satisfaction, Job Performance, Organizational Commitment, Faculty members.

Corresponding author: Hebat Allah Mohammed Salah E-mail: babosha2008@yahoo.com

\section{Introduction}

Emotional intelligence (EI) concept has become an important topic in the psychological literature and attracts much of the public attention in recent years. . Mayer et al., 2016 defined EI as the ability to recognize and regulate emotions by individuals in oneself and in others. ${ }^{2}$ In general, EI refers to a collection of skills such as self-control, determination, self- motivation and sensitivity to the feelings of others. This new dimension of intelligence has received much attention during the last two decades; professional success is more affected by EI than the Intelligence Quotient (IQ), the traditionally used measure of intelligence. ${ }^{3}$

In the teaching profession, the most forward-thinking educators realize the 
critical role of EI in higher education, not just for students but also for the vitality of the university as a whole Faculty members with high EI are optimistic, adaptable, and enthusiastic. They have better communication skills, better ability to conflict resolutions as well as better impulse and self-control. In addition, highly EI staff can facilitate a positive atmosphere during the lecture and influence students with positive behaviors. ${ }^{4}$ It has been concluded that EI is very important in ensuring teachers' effectiveness and job satisfaction. ${ }^{5}$

Furthermore, researchers clarified that EI is a key factor in increasing organizational commitment. ${ }^{6,7}$ It has been reported that an organization's success does not depend only on how it develops employees' competencies but also on how it develops commitment toward the organization. ${ }^{8}$ Organizational commitment has been recognized as one of the most important indicators and factors for success in higher education institutions and it is also one of the vital factors for organizational survival and effectiveness. ${ }^{9}$

In Egypt, seeking to improve the education quality and university accreditation, the role of today's faculty members becomes extremely challenging. They become overwhelmed with multiple tasks rather than teaching such as conducting researches for promotion, attending seminars, project presentations and engaging in students and community services. They also have to cope with students' discipline and behavioral problems and pressures from uncooperative administrations. Such an environment can create psychological and physical distress among them and can also alter their job satisfaction, performance, and commitment toward their career. ${ }^{10}$ Thus, all faculty members need to improve their EI skills as they enable them to manage their emotions, to motivate themselves and overcome frustrations. This will help them to be more satisfied and keep an appropriate performance in their career. ${ }^{11}$

It should be noted that although the concept of EI has been observed a rapidly growing interest among modern society, few studies have been conducted on EI in the educational sectors, particularly among faculty members. Jeya and Balakrishnan (2012) found that the overall level of EI among Malaysian lecturers was average and that the level of EI improved with age and teaching experience. ${ }^{5}$ In Egypt, Badawy and Mariam (2015) examined the impact of EI on job satisfaction among the academicians in four private universities and found no significant association between both of them; however, they found a positive association between EI and age. ${ }^{12}$ To our knowledge, there is a sacristy of Egyptian researches regards EI among faculty members in public universities. It would be beneficial to estimate the level of EI among staff working there and to identify various factors that might affect the EI level.

Meanwhile, numerous researches about the relationship between EI and job satisfaction, job performance and organizational commitment revealed mixed findings. Some researchers have enumerated a strong association between EI measures and job satisfaction. ${ }^{13}$ Other researches reveal a significant positive association between EI and job performance. $^{14}$ While other studies concluded that there was no relationship between EI and job satisfaction. ${ }^{15}$ Also, Samaneh et al. (2011) found that EI did not have any direct or indirect effects on organizational commitment among employees in an Iranian organization. ${ }^{6}$ Due to the conflicting results about the relationship between EI and job satisfaction, job performance and organizational commitment and due to 
paucity of the Egyptian researches in this area; particularly in the educational sectors, the current study was conducted.

Based on the articulated objectives of the study, the following research questions were addressed in the study: What is the level of EI among medical faculty members? What are the different factors that might alter the EI level among the study group? Is there a correlation between EI and job satisfaction among the study group? Is there a correlation between EI and organizational commitment among the study group? Is there a correlation between EI and job performance among the study group?

\section{Objective}

To estimate the level of EI among staff at the faculty of medicine at Ain Shams University, to determine sociodemographic and work-related variables that might affect EI level and lastly to find out the relation between EI and job satisfaction, job performance and organizational commitment among the studied group.

\section{Method}

Study design: A cross-sectional study was adopted to fulfill the purpose of the study.

Study setting and time: The present study was carried out at the Faculty of Medicine at Ain Shams University in 9 months duration from June 2018 to Feb 2019. Faculty of medicine at Ain Shams University was founded in 1947. It is considered one of the leading Egyptian public universities that contribute to the social and economic development of the nation. It was chosen because it enrolls a huge number of students and employs a large number of staff. In the academic year 2017/2018, the university had 5,500 staff including academic and clinical ones served more than 6000 undergraduate students over the 6 years of undergraduate teaching. 16
Study subjects: Faculty members as instructors, assistant lecturers, lecturers, assistant professors, and professors who were working during the academic year 2018-2019 and involved in teaching undergraduate students, were included in the study. They were recruited from various academic and clinical departments in the faculty. Exclusion Criteria: staff with less than one year of teaching experience were excluded from the study.

Sample size: Using Open Epi version 3.01program based on the proportion of faculty members who had high emotional intelligence which was $26 \%$ (Abbasi et al.,2018) ${ }^{17}$, this yield a sample size of (281). The sample size was increased to include (323) participants to account for non-response among staff members, taking into consideration that sample size was calculated with a confidence level of $95 \%$ and a margin of error $\pm 5 \%$. Our sample was (300) participants consisted of (158) academic and (142) clinical members.

Study sample: three hundred twenty-three (323) participants were selected through a convenience sampling technique. Nearly 93\% (300) of them responded. The reasons for non-participating were lack of time and refusal.

Study Variables: Independent variables of the current study are socio-demographic characteristics, work-related variables, and emotional intelligence, while the dependent variables are Job satisfaction, job performance, and organizational commitment.

Operational definitions for study variables:

Emotional intelligence (EI) refers to 'someone's ability to perceive, understand and manage their feelings and emotions. There are five categories of $\mathrm{EI}^{18}$

1-Self-awareness: It is the capacity to conceive and understand personal moods and emotions, and their influence on 
postponing judgment and to think before acting.

2-Self-regulation: the management ability of one's disruptive or negative emotions, and to adapt to changes in circumstance.

3-Internal motivation: a passion to selfmotivate, with a focus on performing internal or self-gratification as opposed to external reward or praise.

4-Social awareness: the ability to manage the emotions of others through emotional conception.

5-Social skills: the ability to manage relationships and build networks, and to find common ground and build rapport.

Job satisfaction: According to Weiss (2002), job satisfaction refers to how well a job provides fulfillment of a need or want, or how well it serves as a source or means of enjoyment. ${ }^{19}$ Hendee, 2002 in his model of job satisfaction stated that job satisfaction is affected by two factors: organizational factors and personal factors, he added EI as a personal factor which along with other personal factors such as gender, education, demographic characteristics, etc., affects one's job satisfaction. ${ }^{20}$.

Job performance: It can be defined as the elements that the organization assigns an employee to do; it is also defined as achievement of organizational goals, the fulfillment of organizational expectations and accomplishment of the organizational ability. ${ }^{21}$ EI develops innovational creativity in individuals, so it enhances people's job performance.

Organizational commitment: Meyer et al. $(2006)^{22}$ identified employee commitment as the emotional attachment between the employees and their organizations which can be characterized by three components: (1) Affective commitment: refers to individuals' positive feelings and attachment towards the organization. (2) Continuance commitment relates to how much employees have the feelings to stay at their organization and (3) Normative commitment; relates to individuals' feelings of obligation and loyalty with the organization.

A structured standardized selfadministrated Questionnaire was used to collect the data. The questionnaire consisted of five sections. Section A, gathered information on the respondents' demographic and job characteristics such as age, gender, marital status, working position and years of experience, sections $\mathrm{B}, \mathrm{C}, \mathrm{D}$, and $\mathrm{E}$ consisted of standardized measures of emotional intelligence, job satisfaction, job performance, and organizational commitment respectively.

An emotional intelligence test was adopted from The English version of Siberia Schering's EI Standard Questionnaire. ${ }^{23}$ It consists of 15 items and examines five aspects of EI: (1) Self-awareness (Questions 1, 8, 11) (2) Self-Regulation (Questions 2, 4, 7) (3) Self-motivation (Questions 6, 10, 12); (4) Social awareness (Questions 3, 13, 15) and (5) Social skills (Questions 5, 9, 14). The responses on the scale were rated on 5 point scale ranging from $1=$ strongly disagree to $5=$ strongly agree. The total scores on the scale range from 15 to 75 , with higher scores reflecting higher levels of EI. In addition; 15-34 was a low score, 35-55 indicated a moderate score and 56-75 indicated a high score of EI. The instrument previous reliability was reported by Schutte et al. ${ }^{24}$ Cronbach's alpha of EIS ranged from 0.87 to 0.90 . The instrument was validated by Akpochafo $^{25}$, the instrument content validity was $79.59 \%$ and the construct validity range between 0.45 and 0.96 .

The English version of the Job Satisfaction Survey (JSS) developed by Spector, 1997 and it is used to measure job satisfaction level. ${ }^{26}$ It has been used in many studies as a standardized measure for job satisfaction in various organizations. ${ }^{27,28}$ It contains 36 
items, 9 facet scales to assess employee attitudes about the job and aspects of the job. Each facet is assessed with 4 items, and a total score is computed from all items. The 9 facets are Pay, Promotion, Supervision, Fringe Benefits, Contingent Rewards (performance-based rewards), Operating Procedures (required rules and procedures), Coworkers, Nature of Work and Communication. The responses are rated on a 6 point scale ranging from $1=$ disagree very much to $6=$ agree very much. The possible total scores on the scale range from 36 to 216 with the $36-$ 108 range meaning dissatisfaction(low satisfaction); 144-216 range meaning high satisfaction; and between 108-144 depicting moderate satisfaction. The instrument's previous reliability and validity were reported by Fesharak ${ }^{29}$; the Cronbach's alpha of (JSS) ranged from 0.75 to 0.90 , the instrument content validity was $76.50 \%$ and the construct validity range between 0.51 and 0.92 .

Job performance was measured using English version of Tseng and Huang's (2011) six-item scale ${ }^{30}$, which is based on Katz and Kahn's conceptualization of the construct in terms of in-role and extrarole behavior in accordance with the Role Behavior Theory. In their model, in-role behavior is "behavior that falls under standard rules in the workplace of an organization," and extra-role behavior represents "the self-evaluative and democratic behavior that is accepted within the organization" The total score was calculated by using mean and standard deviation measures. High reliability and validity revealed from previous studies. ${ }^{31}$

To measure organizational commitment; the English version of Allen and Mayer (1990) organizational commitment questionnaire (OCQ) was adopted. ${ }^{32}$ This is one of the instruments most used internationally in scientific research to assess organizational commitment ${ }^{(33,34)}$. It contains three subscales; the Affective, continuance and normative subscale and each compromised six items, responses to these items were recorded on 5 point scale (1=strongly disagree and 5=strongly agree). In this questionnaire, items 2, 8, 10, 12 , and 14 got the reversed score. Wilson et al previously reported the reliability of the instrument. ${ }^{35}$ The Cronbach's alpha for Affective subscale $=0.85$, for continuous subscale $=0.79$ and for normative subscale $=0.73$.

A pilot study was carried out on $10 \%$ of the sample. The purpose was to ascertain the feasibility of the study and the clarity and applicability of the tools. It also helped to estimate the time needed for filling in the instruments. Based on the results of the pilot, no modifications were needed. Pilot data were excluded from the study results. To test the reliability of the studied scales, Cronbach Alpha was examined. A scale with C. Alpha Coefficient of 0.7 or above is acceptable as stated in past researches. ${ }^{36}$ All the four scales used in this research were over 0.7 , so these scales were fully acceptable.

After explaining the study objectives to participants in order to receive reliable data, each participant received a copy of the tools. The scales were filled in by the participants, while they were on duty and collected immediately after completion.

\section{Data Management and Analysis}

The collected data was revised, coded, tabulated, and introduced to personal computer and then analyzed using SPSS program (Statistical Package for Social Sciences) for Windows Version 22. Data were presented using descriptive statistics in the form of frequencies, percentages, mean and standard deviation. To determine the factors that might be associated with EI score, quantitative variables (personal and job characteristics), independent t-test and one-way analysis of variance (ANOVA) 
were used. Person correlation coefficient was used to test the correlation between study variables. The correlation test was used to determine whether a relationship exists between EI with its subscales and job satisfaction, organizational commitment, and job performance. We considered a correlation low when $r$ was between 0.10 to 0.29 , moderate when $r$ was between 0.30 and 0.49 , and high when $\mathrm{r}$ was between 0.50 and $1.0 .^{37}$ Statistical significance was considered at $\mathrm{P}$-value $\leq 0.05{ }^{26}$ Linear regression was done for Job satisfaction and job performance.

\section{Ethical consideration}

The required ethical and administrative approvals were obtained. An informed consent was obtained from each participant. To assure the confidentiality of data, all the study questionnaires were anonymous.

\section{Results}

The current sample included 300 medical staff who was working at the faculty of medicine Ain Shams University. Their ages ranged between 25 to 63 with a mean of $34 \pm 9$ years, $57.3 \%$ of them were female and more than half $(69.0 \%)$ were married. Participants' Educational level almost distributed equally between bachelor, master and doctoral degrees. $52.7 \%$ were recruited from different academic departments while $47.3 \%$ were from clinical departments, the working duration ranged between 1to 43 with a mean of $8.8 \pm 8.5$ years (Table 1 ).

Figure (1): level of EI and Job satisfaction

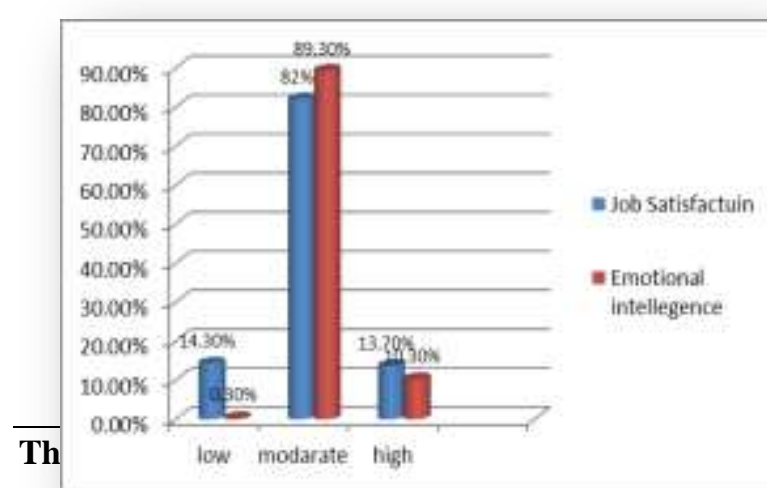

\section{among studied group}

Emotional intelligence score ranged from $31-70$ with a mean of $49.41 \pm 5.32$ : the highest domain was Self-awareness with a mean of $10.82 \pm 1.92$ and the lowest was Self-motivation with a mean of $9.26 \pm 1$. Job satisfaction total score ranged between $89-174$ with a mean of $129.21 \pm 13.32$ with the highest score for Operating condition domain with a mean of $15.84 \pm 3.25$ and the lowest for pay domain with a mean of $13.03 \pm 2.75$. Job performance score ranged

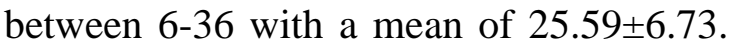
Regarding organizational commitment; Continuance commitment was the highest domain with a mean score of $18.57 \pm 3.28$ and the lowest was for Affective commitment with a mean score of $17.68 \pm 3.07$ (Table 2). It was obvious from figure (1) that the majority of the respondents had a moderate level of emotional intelligence (89.3\%) and a moderate level of job satisfaction (82\%).

There was a statistical significant relationship between EI among studied sample and gender, age, marital status, working department and academic rank as illustrated in (table1); Females, younger individuals (less than 30 years) and those who were working in academic departments got a higher score of intelligence. Divorced respondents had lower scores compared to single and married ones. Regarding academic rank; demonstrators and lecturers had higher EI scores compared to professors, associate professors and assistant lecturers.

Regarding the relation between EI total score and job satisfaction, job performance and organizational commitment; the current study revealed that there was weak but significant positive correlation between EI total score and job satisfaction, job performance, and normative component and affective component of organizational commitment as illustrated in (table 3 ).

$\begin{array}{llll}\text { Vol. } 38 & \text { No. } 2 & \text { April } & 2020\end{array}$


Among the different EI subscales; social skills, social

Table (1): Univariate Analysis of Job \& Personal Characteristics among Studied Sample in Relation to Emotional Intelligence $(\mathrm{No}=300)$

\begin{tabular}{|c|c|c|c|c|c|c|c|c|}
\hline & ariables & No. $(\%)$ & $\begin{array}{r}\text { Em } \\
\text { intellig }\end{array}$ & ore & Test & $\begin{array}{c}\text { p- } \\
\text { value }\end{array}$ & $\begin{array}{r}\text { p-v } \\
\text { post }\end{array}$ & $\begin{array}{l}\text { e for } \\
\text { c test }\end{array}$ \\
\hline & & & & & & & & \\
\hline Age & $<30$ & $121(40.3)$ & 50.58 & 5.84 & $3.19 *$ & $<0.001$ & & \\
\hline & $>=30$ & $179(59.7)$ & 48.60 & 4.78 & & & & \\
\hline $\operatorname{sex}$ & Male & $128(42.7)$ & 47.97 & 4.95 & $4.14 *$ & $<0.001$ & & \\
\hline & Female & $172(57.3)$ & 50.48 & 5.33 & & & & \\
\hline Specialty & Academic & $158(52.7)$ & 50.43 & 5.50 & $3.56^{*}$ & $<0.001$ & & \\
\hline & Clinical & $142(47.3)$ & 48.28 & 4.87 & & & & \\
\hline & Single & $75(25.0)$ & 49.46 & 6.41 & $2.6 * *$ & 0.04 & & \\
\hline Marital & Married & $207(69.0)$ & 49.68 & 4.82 & & & & \\
\hline status & Divorced $^{\#}$ & $9(3.0)$ & 45.44 & 6.63 & & & & \\
\hline & Widow & $9(3.0)$ & 46.77 & 2.22 & & & & \\
\hline & $<6$ & $146(48.7)$ & 49.79 & 5.60 & $0.99 * *$ & 0.37 & & \\
\hline Work & $6-12$ & $91(30.3)$ & 48.79 & 5.28 & & & & \\
\hline & $>12$ & $63(21.0)$ & 49.43 & 4.67 & & & & \\
\hline & Demonstrator & $105(35.0)$ & 50.63 & 5.99 & $4.6 * *$ & 0.01 & ---- $^{\text {\#\# }}$ & 0.50 \\
\hline & Ass .lecturer & $86(28.7)$ & 47.80 & 4.57 & & & 0.00 & 0.01 \\
\hline Job Title & lecturer & $57(19.0)$ & 50.07 & 5.13 & & & 0.50 & ---\#\#\# \\
\hline & Ass.professor & $16(5.3)$ & 47.06 & 5.03 & & & 0.01 & 0.04 \\
\hline & professor & $36(12.0)$ & 49.69 & 4.11 & & & 0.34 & 0.73 \\
\hline
\end{tabular}

* Student $t$ test, ** one way ANOVA test (Bonferroni post hoc test, ${ }^{\#}$ reference group is divorced, ${ }^{\# \#}$ reference

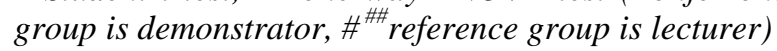

awareness, and self-awareness were significantly correlated with job performance, while only social awareness was found to be significantly correlated with job satisfaction. As regards organizational commitment; social skills and self-motivation were positively correlated with normative commitment while social awareness was the only subscale that correlated significantly to continuous commitment, and selfmotivation was the only one to be correlated to affective commitment as shown in (table 3).

Multiple regression analysis was done to explain and explore variables that might affect job satisfaction and job performance. For an explanation of variation in job satisfaction, different socio-demographic variables were tested including age, sex, marital status, and work duration, also EI, job performance and commitment were tested. By excluding variables that might not affect job satisfaction (depending on $\mathrm{R}^{2}$ ). Social awareness, self-awareness, and self-motivation (domains of EI), job performance and continuance commitment explain $12 \%$ of the variation in job satisfaction $\left(\mathrm{R}^{2}=.121, \mathrm{~F}=8.08, \mathrm{P}<0.05\right)$.

By testing different socio-demographic variables including age, sex, marital status, and work duration, also EI and commitment to explain the variation in job performance. Age, sex, marital status, social awareness, social skills, selfawareness, self-motivation, self-regulation (domains of EI) and continuance commitment explain $15 \%$ of the variation in job performance $\left(\mathrm{R}^{2}=.147, \mathrm{~F}=4.99\right.$, $\mathrm{P}<0.05$ ). (Table 4)

\section{Discussion}

The analysis of this study revealed several interesting points; first, concerning the level of EI among the studied group; the majority of respondents (89.3\%) had a 
moderate level of EI. This result is incongruent with

Table (2): Level of EI, Job Satisfaction, Job Performance and Organizational Commitment among the Studied Group by Mean and SD

\begin{tabular}{|c|c|c|c|}
\hline Targeted Character & Mean \pm SD & Min. & Max. \\
\hline Emotional intelligence total score & $49.41 \pm 5.32$ & 31.0 & 70.0 \\
\hline $\begin{array}{cl}\text { Emotional intelligence subscales } \\
\text { - } & \text { Self -awareness } \\
\text { - } & \text { Self- regulation } \\
\text { - } & \text { Self -motivation } \\
\text { - } & \text { Social awareness } \\
\text { - } & \text { Social skills } \\
\end{array}$ & $\begin{array}{c}10.82 \pm 1.92 \\
9.73 \pm 1.65 \\
9.26 \pm 1.88 \\
9.93 \pm 1.93 \\
9.68 \pm 1.66\end{array}$ & $\begin{array}{l}5.0 \\
4.0 \\
4.0 \\
4.0 \\
5.0\end{array}$ & $\begin{array}{l}15.0 \\
15.0 \\
15.0 \\
15.0 \\
15.0\end{array}$ \\
\hline job satisfaction total score & $129.21 \pm 13.32$ & 89.0 & 174.0 \\
\hline $\begin{array}{ll}\text { Job satisfaction domains } \\
\text { - } & \text { pay domain } \\
\text { - } & \text { promotion domain } \\
\text { - } & \text { supervision domain } \\
\text { - } & \text { Fringe benefit domain } \\
\text { - } & \text { Cowerating condition domain } \\
\text { - } & \text { Nature of work domain } \\
\text { - } & \text { communication domain } \\
\text { - } & \text { Contingent reword domain } \\
\end{array}$ & $\begin{array}{l}13.03 \pm 2.75 \\
13.49 \pm 3.07 \\
13.96 \pm 2.53 \\
14.05 \pm 2.62 \\
15.84 \pm 3.25 \\
15.68 \pm 2.68 \\
15.00 \pm 3.16 \\
14.00 \pm 3.27 \\
14.16 \pm 3.00 \\
\end{array}$ & $\begin{array}{l}7.0 \\
5.0 \\
7.0 \\
6.0 \\
6.0 \\
9.0 \\
4.0 \\
7.0 \\
7.0 \\
\end{array}$ & $\begin{array}{l}22.0 \\
24.0 \\
20.0 \\
20.0 \\
24.0 \\
23.0 \\
22.0 \\
23.0 \\
24.0 \\
\end{array}$ \\
\hline Job performance score & $25.59 \pm 6.73$ & 6.0 & 36.0 \\
\hline \multicolumn{4}{|l|}{ Organizational Commitment } \\
\hline $\begin{array}{ll} & \text { Affective domain } \\
\text { - } & \text { Normative domain } \\
\text { - } & \text { Continuance domain }\end{array}$ & $\begin{array}{l}17.68 \pm 3.07 \\
17.75 \pm 3.18 \\
18.57 \pm 3.28\end{array}$ & $\begin{array}{c}8.0 \\
10.0 \\
9.0\end{array}$ & $\begin{array}{l}46.0 \\
27.0 \\
30.0\end{array}$ \\
\hline
\end{tabular}

the findings of Nasir et al.,2011 $1^{38}$, also agreed with Abbasi et al., $2018^{39}$ who found that most of the staff in Ardabil University of medical science, with $(86 \%)$ had the EI in moderate level, and contradict the findings of El-Sayed et al, $2014^{40}$ who found the majority of nursing faculty members in Zaqaziq university experienced low level of EI, the authors attributed that finding to the deficient curriculum that didn't adopt EI skills throughout the academic years of study as well as absence of any training courses on EI for faculty members. Meanwhile, a recent study was conducted in 2013 by Hans et al. ${ }^{41}$ in a private educational institution in Muscut and reported a high level of EI among teachers. The above variations in the EI level could be attributed to the difference in the study setting, population under study and the tool used for measuring EI.

Among the five subscales of EI; the current study revealed that Self-awareness had the highest mean $(10.82 \pm 1.92)$ followed by social awareness $(9.93 \pm 1.93)$ and the lowest was Self-motivation with mean of $(9.26 \pm 1.88)$. Similar results were reported by Bakr and Safaan, 2012 and Mohammed,2011. ${ }^{42,43}$

As regard socio-demographic and workrelated variables that might affect EI level: first, It was surprising to find that younger staff members (less than 30 years) had a higher level of EI compared to older ones. A similar result was obtained by Riaz et al, 2014 . $^{44}$ This is because it might be that older individuals are stubborn and inflexible in their thoughts and actions and can't change their thinking patterns. This 
Table (3): Correlation Coefficients between EI Total Score \& Its Subscales with Job Satisfaction, Organizational Commitment and Job Performance

\begin{tabular}{lcccccc}
\hline & $\begin{array}{c}\text { Emotional } \\
\text { Intelligence }\end{array}$ & $\begin{array}{c}\text { Self - } \\
\text { Awareness }\end{array}$ & $\begin{array}{c}\text { Self- } \\
\text { Regulation }\end{array}$ & $\begin{array}{c}\text { Self- } \\
\text { Motivation }\end{array}$ & $\begin{array}{c}\text { Social } \\
\text { Awareness }\end{array}$ & $\begin{array}{c}\text { Social } \\
\text { Skills }\end{array}$ \\
\hline $\begin{array}{l}\text { Job } \\
\text { satisfaction }\end{array}$ & $0.12^{*}$ & 0.05 & 0.01 & 0.04 & $0.16^{* *}$ & 0.06 \\
\hline $\begin{array}{l}\text { Normative } \\
\text { commitment }\end{array}$ & $0.16^{* *}$ & 0.09 & -0.03 & $0.17^{* *}$ & 0.11 & $0.13^{*}$ \\
\hline $\begin{array}{l}\text { Continuance } \\
\text { commitment }\end{array}$ & 0.09 & 0.01 & -0.05 & 0.04 & $0.19^{* *}$ & 0.09 \\
\hline $\begin{array}{l}\text { Affective } \\
\text { commitment }\end{array}$ & $0.14^{*}$ & 0.01 & 0.04 & $0.16^{* *}$ & 0.09 & 0.11 \\
\hline $\begin{array}{l}\text { Job } \\
\text { performance }\end{array}$ & $0.14^{*}$ & $0.20^{* *}$ & -0.05 & -0.10 & $0.18^{* *}$ & $0.15^{* *}$ \\
\hline
\end{tabular}

*Correlation is significant at the 0.05 level, **Correlation is significant at the 0.01 level

finding unexpectedly opposes the previous

literature as most of the researches demonstrated that as people grow up their EI gets higher. ${ }^{40}$ Levenson, $2011^{45}$ also concluded that EI can sharpen as people enter in their 60s, giving older individuals benefit in their jobs and personal life. On the other hand, an Egyptian study conducted by El Badawy et al., $2014^{46}$ among faculty members revealed no significant association between EI and age, the authors argued that EI is an individual ability which anyone can strengthen and not related to a specific age.

EI score was significantly different between females and males, with females reporting higher EI level. This might be attributed to the fact that females tended to be more expressive than males. They are believed to understand and recognize other's emotions better and own greater empathy as being more perceptive. Similar results were reported by Ahmed, 2015. ${ }^{47}$ On contrary, Shahzad and Bagum, 2012 witnessed males as higher on EI level while Shehzad and Mahmood, 2013 $3^{49}$ declared no difference of emotional intelligence from a gender perspective.

The present work revealed a significant association between marital status and EI Level; divorced respondents had lower scores compared to single and married ones. A logical explanation would be that individuals with higher EI were blessed with good communication skills and better recognition and control of their emotions, thus enhanced the relationship with their partners and decreased marital conflicts. Ciarrochi et al. (2001) clarified that EI enabled individuals to succeed in their personal relationships as well as their work. ${ }^{50}$ The above result contradicts the findings of Mohamed and Nagy ,2017 $7^{51}$ who found no significant relations between both variables among academic staff.

As regards academic rank among participants; it was found that demonstrators and lecturers had higher EI scores compared to professors, associate professors and assistant lecturers. Ahmed, $2015^{47}$ reported the same results, while $\mathrm{El}$ Sayed et al, $2014^{10}$ revealed that Lecturers and Assistant professors had more EI and sense of self-efficacy than demonstrators and Assistant lecturers. No significant association was detected between EI and work duration in the current work, similar findings were reported by Mohammed, $2011 .{ }^{43}$ On contrary, El-Sayed et al, $2014^{10}$ found a significant relation between EI and teaching experience.

Concerning the level of job satisfaction; It is noteworthy that the result of the present study revealed that the majority of faculty members in the studied group $(82 \%)$ were moderately satisfied with their job. This 
result is Similar to Plastsidou and Diamantopoulou $(2009)^{52}$ who concluded that Greek academics were moderately satisfied with their job, and; contradict the findings of Bozeman and Gaughan $(2011)^{53}$ who reported that majority of faculty members had a high level of job satisfaction.

The result of Pearson coefficient correlation revealed a weak positive significant correlation between EI and job satisfaction. This means that faculty members with higher levels of EI are more satisfied with their job organization. The reason behind that could be that respondents with higher levels of EI use mechanisms that helped them to adapt to the poor conditions in the faculty environment such as inadequate resources, work overload and teaching tasks without adequate reward. Those with a low level of EI, on the other hand, lacked this ability to adapt properly to this critical situation and become less satisfied. Also, high emotional intelligence respondents were able to acknowledge, manage, and use their emotions to eliminate ensuing barriers and improve their career horizons than those with low emotional intelligence.

The above findings are incongruent with that reported by Long et al. (2016). ${ }^{54}$ In addition, Masroor $(2009)^{55}$ conducted a study to analyze the relationship between EI and job satisfaction among administrative staff in higher education institutions in Malaysia and found a positive relationship between the two variables' On contrary, El Badawy et al. $(2014)^{46}$ found that EI was not related to Job satisfaction, while Gill et al. $(2012)^{56}$ revealed a negative correlation between EI and job satisfaction of Faculty's member. A possible cause for such a contradiction in the findings of the above studies may be due to the different statistical tools used for evaluation of EI and job satisfaction.
Among the five subscales of EI; only social awareness was found to be significantly correlated with job satisfaction as evident from the result of Pearson correlation coefficient which found a weak but significant positive correlation between both variables $(\mathrm{r}=0.16$ with a P-value 0.01).This finding indicated that the ability of faculty members to understand and visualize the emotional constituents of other people has a relationship with their job satisfaction. It could be explained that faculty members with high social awareness are better equipped in evaluating and setting the emotions of their students. This certainly helped to foster positive and nurturing student-teacher relationships resulting in a greater degree of job satisfaction. This finding agrees with work of Mousavi et al., $2012^{57}$ who revealed that social awareness and empathy were predictors of job satisfaction and contradict the finding of Afzaal and Taha, $2013^{58}$ who pointed that among the five components of EI; only self-management and self-awareness had positive significant correlation with job satisfaction.

Interestingly multiple regression results indicate that social awareness, selfawareness, self-motivation (domains of EI), job performance, and continuance commitment explain $12 \%$ of job satisfaction. Although other studies like Long et al. $(2016)^{54}$ found more interesting results, authors found $29 \%$ of the variation in job satisfaction was significantly explained by EI in teachers. This difference in variation may be due to differences in tools used for measurement of EI and job satisfaction as well as variation in the population under study.

Regarding the relation between EI and job performance; the results of the current work showed that there was a positive significant correlation between EI and job 
performance. This means that Individuals

with a higher level of EI are more likely to

Table (4): Results of Multiple Linear Regression Analysis for Explanation of The Relationship Between EI Subscales and Job Satisfaction, Job Performance and Commitment

\begin{tabular}{|c|c|c|c|c|c|c|}
\hline Model & B & Sig. & $\begin{array}{c}\mathbf{R}^{2} \\
\text { Change }\end{array}$ & $\mathbf{F}$ & $\begin{array}{c}\text { Model } \\
\mathbf{R}^{2}\end{array}$ & Sig. \\
\hline \multicolumn{7}{|c|}{ Multiple linear regression for job satisfaction } \\
\hline (Constant) & 100.66 & 0.00 & ------- & \multirow{7}{*}{8.08} & \multirow{7}{*}{0.12} & \multirow{7}{*}{$<0.001$} \\
\hline Job performance & .59 & 0.00 & 0.097 & & & \\
\hline Continuance commitment & .35 & 0.12 & 0.011 & & & \\
\hline Domains of EI & & & & & & \\
\hline Social awareness & .62 & 0.12 & 0.008 & & & \\
\hline Self-awareness & .34 & 0.39 & 0.001 & & & \\
\hline Self-motivation & .46 & 0.24 & 0.004 & & & \\
\hline \multicolumn{7}{|c|}{ Multiple linear regression for job performance } \\
\hline (Constant) & 11.61 & 0.00 & ---- & \multirow{12}{*}{4.99} & \multirow{12}{*}{0.147} & \multirow{12}{*}{$<0.001$} \\
\hline Age & 1.48 & 0.07 & 0.023 & & & \\
\hline Sex* & 1.87 & 0.02 & 0.032 & & & \\
\hline \multicolumn{7}{|l|}{ Marital status** } \\
\hline Married & 1.44 & 0.13 & & & & \\
\hline Divorced and widow & 1.37 & 0.43 & 0.020 & & & \\
\hline \multicolumn{4}{|l|}{ Domains of EI } & & & \\
\hline - Self-awareness & 0.45 & 0.03 & 0.022 & & & \\
\hline - Self-regulation & -0.12 & 0.60 & 0.001 & & & \\
\hline - Self-motivation & -0.47 & 0.03 & 0.011 & & & \\
\hline - Social awareness & 0.41 & 0.05 & 0.018 & & & \\
\hline - Social skills & 0.42 & 0.08 & 0.011 & & & \\
\hline - Continuance commitment & 0.19 & 0.11 & 0.008 & & & \\
\hline
\end{tabular}

*Reference group is male

**Reference group is single

perform better in their work, this finding confirms the work of Amgad (2018) ${ }^{59}$ who found a significant association between EI and educational performance of university teachers in Quetta, Baluchistan. It could be justified that individuals blessed with high EI are more adaptive to various situations and obstacles faced in their workplace. Besides, they learned consistently while encouraging and inspiring others, thus performing better in their career. ${ }^{60}$

Among the subscales of EI, social awareness, social skills and self-awareness were significantly correlated with job performance. In addition, multiple regression results revealed social awareness, social skills, self-awareness, self-motivation, self-regulation (domains of EI) and continuance commitment explain $15 \%$ of the variation in job performance $\left(\mathrm{R}^{2}=.147, \mathrm{~F}=4.99, \mathrm{P}<0.05\right)$.

This finding suggested that faculty members who can better manage their own emotions and emotions of others and those with high social skills presumably succeed in communicating their ideas, goals, and purposes to their students in interesting and productive ways. This result confirmed the findings of Rahmat et al. $(2014)^{61}$ who reported a significant relationship between the faculty members' self-awareness, social awareness and ability to organize the relationships with their educational performance. On the 
contrary, Codier et al (2008) $)^{62}$ found no significant relation between EI and job productivity among clinical staff nurses.

Regarding organizational commitment among the studied group; The results of the current study revealed that continuance component had the highest mean score $(18.57 \pm 3.28)$ followed by normative component, while affective component had the lowest mean score (17.68 \pm 3.07$)$. The highest score for continuous component could be attributed to the fact that in Egypt, there are fewer job opportunities and faculty of medicine as a higher education institution is the major employer in such an area. Thus, faculty members especially academic staff committed to the organization due to the fear that they will not find a job or a job that pays the same in that area. Joolideh and Yeshodhara $(2009)^{63}$ studied the organizational commitment of the teachers in India and Iran and unconcealed that Iranian teachers had a better organizational commitment in the continuance and normative components whereas Indian teachers were found to have a better organizational commitment in the affective component.

Regards the relation between EI and organizational commitment; Pearson coefficient correlation test revealed that normative component and affective component of organizational commitment had a positive significant correlation with EI. This means that staff with higher EI is more willing to exert substantial effort on behalf of the organization and feel happier as they work with the organization. A logical explanation would be that staff that had a higher level of EI may have a better relationship with their colleges and supervisors. Thus, it became more committed to their work as they would view their relationship with their organization as an extension of the relationship they had with coworkers and managers. Ssesanga and Garrett $^{64}$ conducted a study in 2005 among university professionals in Uganda and suggested that academics with high EI would perceive high satisfaction and tend to feel more emotionally attached to their organization. On the contrary, other studies have reported that EI had an insignificant influence on organizational commitment (Shamsuddin \& Ujang, 2008). ${ }^{65}$

Among the subscales of EI; social skills and self-motivation were significantly correlated with normative commitment. This meant that staff members who are highly motivated and those with good interpersonal relationships are more loyal and committed to their organization. The above result can be in line with the findings of Zeidner et al. 2004. ${ }^{66}$ Regarding continuous commitment; social awareness was the only subscale that related significantly to it, while selfmotivation was the only one to be significantly correlated to affective commitment. According to Abraham (2016), the social relationship within the organizations increases employee commitment and their desire to maintain and keep their job. ${ }^{67}$

\section{Conclusion}

The result of the current study revealed that the majority of medical staff had a moderate level of EI as well as job satisfaction, among the components of organizational commitment; Continuance commitment was the highest. The study also revealed that there is a positive correlation between EI and job satisfaction, job performance and organizational commitment of the respondents which also depicted that faculty members who had a higher level of EI were more productive and feeling more satisfied and loyal to their jobs than others.

Recommendations and Practical implications of the study: 
Based on the above findings and discussion, the following suggestions should be considered: The present results revealed that faculty members who had higher EI were more productive and satisfied with their work. Therefore, counseling and personnel psychologists should be used by various universities to enhance the EI of their staff by arranging proper awareness workshops and lectures for staff members to increase their social skills. It will significantly enhance their educational performance, satisfaction, and commitment to their career. The study also concluded that EI was positively related to organizational commitment. Thus, it's highly suggested that to retain talented and knowledgeable university teachers, universities need to select faculty members who have high EI, because this may have a positive impact on the extent to which they can succeed in retaining their valuable and talented workforce. Finally, the findings in this study provided support for age and gender differences among participants concerning their EI, with younger participants (less than 30 years old) and females achieve higher EI level. It is implied that younger individuals and female staff might have higher abilities to recognize and regulate self and other's emotions and would communicate more effectively with their students. Thus, its highly advised that faculty administration provide more chances for younger staff and female members to participate in the teaching process and communication with their students thus will help the faculty to achieve its goals and productivity.

Also, the research confirmed the importance of EI to enhance job satisfaction, performance and organizational commitment among faculty members. Following recommendations are given based on findings; There may be organized EI awareness programs in the faculty to improve the EI among faculty members, specifically for those who scored low levels. It is recommended that, in addition to academic qualifications, the personality and emotional characteristics can be considered in the selection procedure of faculty members, as well. Emotional intelligence tests should be utilized in the workplace for giving promotions, staff reviews, recruitment, achievements, etc. Some future recommendations involve longitudinal studies to be conducted to establish the causal association between various factors and EI. Also, surveying private universities and comparing the results with the public ones. Also, further studies are required to evaluate the effect of implementing educational intervention programs to develop and enhance faculty members' EI abilities.

\section{Limitation of the study}

The present study had several limitations that should be addressed. First; though this study used validated and usable measures, the questionnaire used was a selfassessment questionnaire. The disadvantage of self-assessment tests is that participants can change their answers to represent the desired image of them. Second, Being a cross-sectional study, causal associations could not be established between factors and EI. Third, a convenience sample was adopted to select participants, so the results cannot be generalized to the target population. Lastly, this study is conducted only on staff at the faculty of medicine; results might not be the same to other universities and professions.

\section{References}

1. Mayer JD, Roberts RD and Barsade SG .Human abilities and Emotional intelligence. Annual Review of Psychology . 2008 ; ( 59): 507-36.

2. Mayer J.D., Caruso D.R., Salovey P. The ability model of emotional intelligence: 
Principles and updates. Emot. Rev. 2016;8:290-300.

3. Goleman D . Emotional intelligence: Why It Can Matter More Than IQ, The New York Times Book Review .2005; (7):56-89.

4. Hosotani $R$ and Imai $K$. Emotional experience, expression, and regulation of highquality university teachers, Teaching and Teacher Education .2011; (27):139-48.

5. Jeya A, Balakrishnan $M$. The Influence of Demographic Profiles on Emotional Intelligence: A Study on Polytechnic Lecturers in Malaysia, International Online Journal of Educational Sciences .2012;ISSN: 1309-2707

6. Samaneh A, Ali R , Kiaman E , Abdolrahim N and Ebrahim B . Emotional Intelligence and Organizational Commitment: Testing the Mediatory Role of Occupational Stress and Job Satisfaction, Social and Behavioral Sciences .2011; (29):1965-76

7. Amgad S. Emotional Intelligence, Organizational Commitment and Job Performance in Pakistan. Market Forces ,College of Management Science, 2018; Vol. $\mathrm{XIII}$, Issue.

8. Chughtai AA, and Zafar, S. Antecedents and consequences of organizational commitment among Pakistani university teachers, Applied HRM Research.2006; 11 (1): 39-64

9. Bhatnagar J. Predictors of organizational commitment in India: strategic HR roles, organizational learning capability and psychological empowerment, Human Resource Management.2007; 18 (10):1782-1811.

10. El-Sayed SH, El-Zeiny AE and Adeyemo DA. Relationship between occupational stress, emotional intelligence, and self-efficacy among faculty members in faculty of nursing Zagazig University, Egypt, Journal of Nursing Education and Practice .2014; (4):4-18 available online at: www.sciedu.ca/jnep 11. Viriyavid V and Jiamsuchon S. Life Insurance Business Organizations; The relationship between Emotional Quotient (EQ) and leadership Effectiveness. Social and Behavioral Sciences, 2008;301-09 Available online at: http//www.emoeraldinsight.com

12. Badawy $T$ and Mariam M. Assessing the Impact of Emotional Intelligence on Job Satisfaction, An Empirical Study on Faculty
Members with Respect to Gender and Age, international Business Research,2015; Vol 8, No 3 , available online at: http://dx.doi.org/10.5539/ibr.v8n3p67

13. Mandip G, Ali SF, Barkha G, Godulika D, and Lad Kamna L . Emotional intelligence as a forecaster of job satisfaction amongst the faculty of Professional Institutes of Central Indian City, Indore. ISCA Journal of Management Sciences, 2012; 1(1), 37-43

14. Trivellas P, Gerogiannis V and Svarna S . Exploring workplace implications of Emotional Intelligence (WLEIS) in hospitals: Job performance and turnover Intentions, Procedia, Social and Behavioral Sciences.2013; (73): 701-709

15. Fatemeh S G, Ali R Z, Fatemeh A, Seyed $G A$ and Maryam $Z$. Evaluation of Emotional Intelligence and Job Satisfaction in Employees of Kashan Hospitals, Nurse Midwifery Stud. 2014;3(1): 11-27.

16. Memorial book of 50th anniversary of establishing Ain Shams Faculty of medicine, School Mission and Objectives. Archived June 18, 2008, at the Way back Machine

17. Abbasi V, Zakeri A, Amani F, Molaei B. Assessment of emotional intelligence in medical university staff in Ardabil: Northwest of Iran. Int J Adv Med 2018;5:776-9.

18. Cary .C and Goleman .D. The Emotionally Intelligent Workplace: How to Select for, Measure, and Improve Emotional Intelligence in Individuals, Groups, and Organizations. Annual Review of Psychology. 2015 ; ( 59): 407-37.

19. Weiss, H. M. 'Deconstructing job satisfaction: separating evaluations, beliefs and affective experience', Human Resource Management Review, 2002;22: 173-194.

20. Hendee, S.S. ProQuest Information and Learning Company, 2002; MI 48106-1346.

21. Mihalcea, A. Leadership, Personality, Job Satisfaction and Job Performance. Procedia Social and Behavioral Sciences, 127, 443-447. https://doi.org/10.1016/j.sbspro.2014.03.287

22. Meyer J, Becker T and Van Dick R. Social Identities and Commitments at Work: Toward an Integrative Model, Journal of Organizational Behavior, 2006, Vol. 27, pp. 665-683. 
23. Mansouri R . Emotional Intelligence Questionnaire Sybrya Schering standardization among staff at Tehran University, Iran: J Teach Learn.2000; 6(2):32-60.

24. Schutte N S, Malouff J M, Hall LE, Haggerty D J, Cooper JT, Golden C J, Dornheim L. Development and Validation of a Measure of Emotional Intelligence. Personality and Individual Differences.2004; 25(2): 167177.

25. Akpochafo G O. Emotional Intelligence and Self Efficacy as Correlates of Career Commitment in Nigeria. An International Multi-Disciplinary Journal. 2011 Jan; 5(1): 212-225.

26. Spector PE . Job Satisfaction: Application, Assessment, Causes, and Consequences. United Kingdom: Sage Publications Ltd,1997.

27. Musenze Abaasi. Psychometric Evaluation of Job Satisfaction Scale in Uganda's Teacher Population Sample.Global Journal of humansocial science: 2016; 33, 282-290.

28. Astrauskaité, M., Vaitkevičius, R., \& Perminas, A. Job Satisfaction Survey: A Confirmatory Factor Analysis Based on Secondary School Teachers' Sample. International Journal of Business \& Management,2011; 6(5), 41-50. 6.

29. Fesharak. M. Reliability and validity of "Job Satisfaction Survey" questionnaire in military health care workers , Journal of Military Medicine, 2012.; 13(4):241-246

30. Tseng S M and Huang J S . The Correlation between Wikipedia and Knowledge Sharing on Job Performance, Expert Systems with Applications.2011; (38):6118-24.

31. Hou M., Jiang Q., Chen X., Zhu M. Y., Yan X. F., Xiang L. Teacher's emotional intelligence and job performance: the mediating roles of work-family enrichment and active behaviors. Psychol. Dev. Educ, 2014; 30 160-168.

32. Allen N J and Meyer J P . The Measurement and Antecedents of Affective, Continuance and Normative Commitment to the Organization, Journal of Occupational Psychology.1990;( 63): 1-18.

33. Morteza Rajab Pur Farkhani, Dr. Hamid Saremi. The Relationship between Emotional Intelligence and Organizational Commitment among Male Teachers at Elementary Schools in Quchan. International Journal of Life Sciences, 2015; 9 (6) : $41-49$

34. Borhani, F. Study the factors affecting organizational commitment in staff of the Ministry of Culture and Islamic Guidance in Islamic Azad University. Science and Research Branch,2012; 6 (3) : 21 - 29

35. Wilson M, Fred E. K. Bakkabulindi J .Validity and Reliability of Allen and Meyer's Measure of Employee Commitment in the Context of Academic Staff in Universities in Uganda. journal of education and sociology in Afreica,2016; Vol. 14 No. 1

36. Holmes. P. Introduction to Structural Equation Modeling Using LISREL. ACSPRIWinter Training Program,2001.

37. Cohen J, Cohen P, West S, Aiken L. Applied Multiple Regression-Correlation Analysis for the Behavioral Sciences. NJ: Lawrence Erlbaum Associates, 2003.

38. Nasir Z, Mustaffa M and Ahmad R.The Relationship between Emotional Intelligence with Skills Competency and Personal Development among Counseling Teachers in Kulaijaya District, Johor, International journal of fundamental psychology \&social science.2011; 1(1): 17-20.

39. Abbasi V, Zakeri A, Amani F, Molaei B. Assessment of emotional intelligence in

40.medical university staff in Ardabil: Northwest of Iran. Int J Adv Med 2018;5:7769.

41. El-Sayed SH, El -Zeiny AE and Adeyemo DA. Relationship between occupational stress, emotional intelligence, and self-efficacy among faculty members in faculty of nursing Zagazig University, Egypt, Journal of Nursing Education and Practice .2014; (4):4-18 available online at: www.sciedu.ca/jnep

42. Hans A, Mubeen S and AI Rabani S .A study on emotional intelligence among teachers, Int. J. Appl. Innovat.Eng. Manag.,2013; 2(7): 359366.

43. Bakr $M$ and Safaan S.Emotional Intelligence: A Key for Nurses' Performance. J Am Sci.2012 ;8(11):385-393]. (ISSN: 15451003). http://www.jofamericanscience.org.

44. Mohammed F $\mathrm{H}$.Exploring the relationship between emotional intelligence and leadership styles among head nurses at 
zagazig university hospitals, Egypt: Zagazig university.2011; 51,72,77.

45. Riaz F ,Siddique A, Riaz A, Nawaz Y and Shehzadi S .Role of Emotional Intelligence on Job Satisfaction in university teacher ,Academic Journal of Interdisciplinary Studies. 2014;(3): 6 -27.

46. Levenson R . Emotional Intelligence Gets Better With Age. . Emotional intelligence and the career choice process,Journal of workplace, 2011; 24: 256-269.

47. El Badawy TA, Srivastava S and Sadek MB .Assessing the Relationship between Emotional Intelligence, Job Satisfaction and Organizational Learning Capability in Private Higher Educational Institutions in Egypt and India: A Comparative study, International Journal of Business Administration,2014; Vol. 5, No. 6; available online at: www.sciedu.ca/ijba

48. Ahmed $\mathrm{H}$. emotional intelligence and job satisfaction among university teachers, Int. J. Educ. Stud.2015; 02 (02) :95-100 available on line at : http://www.escijournals.net/IJES

49. Shahzad $S$ and Bagum N . Gender differences in trait emotional intelligence: $\mathrm{A}$ comparative study. Business Review,2012; 7(2), 106-112.

50. Shehzad S and Mahmood, N. Gender differences in emotional intelligence of university teachers. Pakistan Journal of Social and Clinical Psychology,2013; 11(1), 16-21.

51. Ciarrochi J, Forgas JP and Mayer JD .Emotional intelligence in everyday life: A Scientific Inquiry.Philadelphia, PA, US: Psychology Press/Taylor \& Francis; 2001.

52. Mohamed S and Nagy F . Emotional Intelligence and Job Stress among Academic Members at Faculty of Nursing - Cairo University ,Journal of Nursing and Health Science,2017; (IOSR-JNHS) e-ISSN: 2320 1959.p- ISSN: 2320-1940 Volume 6, Issue 1 Ver. IV PP 10-19 available online at:www.iosrjournals.org DOI: 10.9790/19590601041019

53. Platsidou $M$ and Diamantopoulou G.Job satisfaction of Greek university professors: Is it affected by demographic factors, academic rank and problems of higher education? In G. K. Zarifis, (Ed.) Educating the Adult Educator: Quality Provision and Assessment in Europe",
Conference Proceedings, Thessaloniki: Grafima Publications, 2009;pp. 535 - 545

54. Bozeman B and Gaughan M. Job Satisfaction among University Faculty: Individual, Work, and Institutional Determinants, The Journal of Higher Education,2011; Vol. 82, No. 2 (MARCH / APRIL 2011), pp. 154-186 https://www.jstor.org/stable/29789513

55. Long $\mathrm{C}$, Yaacob $\mathrm{M}$ and Chuen, $\mathrm{T}$.The Impact of Emotional Intelligence on Job Satisfaction among Teachers. International Journal of Management, Accounting and Economics.2016; 3(8), 544-552.

56. Masroor AM . The Relationships between the Emotional Intelligence and Job Satisfaction: Empirical Findings From Higher Education Institution in Malaysia , Journal of Management and Social Sciences, 2009; Vol. 5, No. 2, Pp. 124-139.

57. Gill et al.. Emotional intelligence as a Forecaster of Job Satisfaction amongst the Faculty of Professional Institutes of Central Indian City, Indore, ISCA Journal of Management Sciences, 2012; Vol. 1(1), pp. 3743.

58. Mousavi S $\mathrm{H}$ et al., The relationship between emotional intelligence and job satisfaction of physical education teachers, Annals of Biological Research: 2012;Vol. 3, No. 2, Pp. 780-788.

59. Afzaal $\mathrm{H}$ and Taha A . An investigation of relationship among emotional intelligence, organizational commitment and job satisfaction: evidence from academics in Brunei Darussalam. International Business Research,2013; 6(3), 217-2283-4015

60. Amgad S. Emotional Intelligence, Organizational Commitment and Job Performance in Pakistan. Market Forces,College of Management Science ,2018; Vol. XIII, Issue.

61. Farh C I, Seo MG and Tesluk P E. Emotional intelligence, teamwork effectiveness, and job performance: The moderating role of job context. Journal of Applied Psychology, 2012;97(4), 1-28

62. Rahmat N , Ghalavandi $\mathrm{H}$ and Jesarati .A Relationship between the faculty members' emotional intelligence and educational performance at Urmia University, European 
Journal of Experimental Biology,2014; 4(1):95-103

63. Codier E , Kooker B and Shoultz J .Measuring the Emotional Intelligence of Clinical Staff Nurses: An Approach for Improving the Clinical Care Environment. Nursing Administration Quarterly, 2008;32 1:

8 - 1411 -

64. Joolideh F and Yeshodhara K. Organizational commitment among high school teachers of India and lran. Journal of Manpower: 2009;22 (7), 593-9

65. Ssesanga, K., \& Garrett, M. R. Job Satisfaction of University Academic: Perspective from Uganda. Higher
Education,2005; 50, 33-56. http://dx.doi. .org/10.1007/s10734-004-6 346-0

66. Shamsuddin $\mathrm{S}$ and Ujang N. The role of attachment in creating the sense of place for traditional streets in Malaysia. Habitat International, 2008;32(3), 399-409

67. Zeidner M Matthews $G$ and Roberts $R$ .Emotional intelligence in the workplace: a critical review. Applied Psychology: An International Review, 2004;53(3), 371-99.

68. Abraham R. Emotional intelligence in organizations: A conceptualization. American psychological Association (APA), 2016 available on line at: https://psycnet.apa.org/record/1999-05491005 . 